\title{
Technology of semi-hard cheese using protein fat simulator
}

\author{
Ekaterina B. Stanislavskaya ${ }^{1}$, Elena I. Melnikova ${ }^{1}$, Arina R. Fedorova ${ }^{1}$, Maksim M. Danyliv ${ }^{1, *}$ and Olga A. Vasilenko ${ }^{2}$ \\ ${ }^{1}$ Voronezh State University of Engineering Technologies, 394036, Voronezh, Russia \\ ${ }^{2}$ Voronezh State Agrarian University named after Emperor Peter the Great, 394087, Voronezh, Russia
}

\begin{abstract}
The annual increase in the production of protein-sensitive dairy products leads to an increase in the available amount of their by-product of production - whey. A promising direction in the implementation of its biotechnological potential is the production of a protein imitator of the fat properties - whey protein microparticulate. The aim of this work was to study the possibility of its use in the technology of semi-hard cheeses. The introduction of a fat simulator in a normalized mixture changes its composition, including the ratio of protein fractions, the ratio of fat to protein, and calcium content. With a mass fraction of microparticulate more than $10 \%$, a flabby clot forms, which is extremely difficult to undergo further processing to obtain elastic cheese grain. High hydration of whey proteins increases the moisture content in the cheese mass after pressing and in the ripening process. Hydrolysis of paracasein and its fractions proceeds more intensively in the cheese with fat simulator. The developed product is characterized by a higher value of the moisture content, which, together with the preservation of the protein clot particles of the simulator by the mesh structure, increases the yield of cheese.
\end{abstract}

\section{Introduction}

The annual increase in the production of proteinsensitive dairy products leads to an increase in the available amount of their by-product - whey. Curd and cheese whey, the volume of which in the Russian Federation exceeds 7 million tons, is a challenging object for food technology [1-3]. Such indicators as shelf life, high microbiological contamination and titratable acidity, low concentration of solids, the presence of specific aromatic components hinder the widespread use of whey for food purposes. At the same time, this food object contains valuable nutrients, including functional ones [4].

Whey proteins are optimally balanced in their amino acid composition, can be a source of biologically active substances that perform protective, structural and other functions in the human body [5]. The development of alternative options for the modification of the whey protein cluster, which allows to efficiently and most fully realize its potential, is an urgent task of the global dairy industry.

A promising direction is to obtain a protein imitator of the fat properties - whey protein microparticulate. The technology for its production includes the purification of whey from casein dust and fat, ultrafiltration, as well as thermomechanical treatment [6-7]. This combination of exposure methods allows obtaining a food dispersion containing spherical particles similar in shape and size to fat globules [8].

The experience of using microparticulates is known both in the Russian Federation and abroad. Using a protein fat mimic allows achievement of numerous positive technological effects. Sour-milk drinks produced using microparticulate are characterized by high organoleptic properties such as thick, creamy consistency even with a low mass fraction of fat [9-11]. Great scientific and practical interest is attributed to the use of microparticulates in the production of protein products: cheeses and curd. Given its relevance, the aim of this work was to study the possibility of using a protein simulator of the fat properties in the technology of semi-hard cheeses.

\section{Methods and Equipment}

Cheese whey obtained in the conditions existing at the Kalacheevsky cheese factory (Kalach, Voronezh oblast, Russian Federation), a protein fat simulator developed on the basis of cheese whey using microparticulation technology, and semi-hard rennet cheese made using Rossiysky cheese technology were selected as objects of this study. Starter cultures and enzyme preparation manufactured by Chr. Hansen were used as technological auxiliary agents, as well as a solution of calcium chloride with a mass fraction of $40 \%$. The process of microparticulation of cheese whey was carried out in the hardware workshop of PJSC Voronezhsky Dairy Plant (Voronezh, Russian Federation). The resulting microparticulate was used to obtain prototypes of normalized milk mixture for the production of cheese.

The indicators of the composition of the study objects, their physico-chemical properties were determined in accordance with the standards in force in

* Corresponding author: max-dan@ yandex.ru 
the Russian Federation. The mass fraction of dry matter was estimated by weight loss in percent when the product sample was dried at a constant temperature. The mass fraction of protein was determined by the Kjeldahl method. To determine the mass share of lactose in the objects of study, the Bertrand method was used. The essence of this method is titration of iron (II) with a solution of $\mathrm{KMnO}_{4}$. Ferrous iron is obtained as a result of the redox reaction of ferrous ammonium sulfates with copper oxide (I), which is formed as a result of the reduction of divalent copper with reducing sugars. Determination of the mass fraction of fat was carried out by the acid method, which consists in isolating fat from the object of study and measuring its amount using a butyrometer.

In order to determine the total concentration of calcium in dairy raw materials, the complexometric method was used. It is based on the reverse titration method: an excess of Trilon B (disodium salt of ethylenediaminetetraacetic acid) is added to the objects of research, which is then bound with a solution of calcium chloride. Active acidity was determined by potentiometric method, and titratable acidity by titrimetric method.

The study of rennet coagulation was carried out according to the method described in GOST ISO 118152015 "Milk. Determination of the total milk-clotting activity of beef rennet." The determination of dynamic viscosity was carried out by tuning fork vibration on an SV-10 vibro-viscometer. The relative strength of the coagulum was determined as the ratio of the ultimate shear stress, estimated using a penetrometer, prototype to control. The mathematical processing of the experiment was carried out by the methods of mathematical statistics according to 5-10 experiments in a triple sequence.

\section{Results}

A distinct feature of the technology of Rossiysky cheese is its high level of lactic acid fermentation. The key stages of its production include the following sequence of technological operations: commissioning and preparation of raw materials, coagulation of milk, processing of a clot and cheese grain, molding and pressing, salting, ripening, preparation of cheese for sale. For the production of Rossiysky cheese, pasteurized normalized milk is used. In the studies performed, part of the skimmed milk in the normalized milk mixture was replaced with the protein fat simulator (Table 1).

The use of ultrafiltration in the preparation of a simulator leads to an increase in the proportion of solids, including proteins and calcium, in comparison with native cheese whey. The introduction of the microparticulate into a normalized mixture changes its composition, in particular, such important indicators for cheese making as the ratio of protein fractions, the ratio of fat to protein, and others (Table 2).

Normalized milk, including that with the microparticulate of whey proteins, was fermented, a milk-clotting enzyme preparation and a solution of calcium chloride were added. The composition of the starter culture for Rossiysky cheese includes mesophilic lactococci (Lac.lactis, Lac. cremoris) and lactic acid bacilli (Lb. plantarum, Lb. casei, Lb.bulgaricus). Coagulation of milk was carried out at a temperature of $32-34{ }^{\circ} \mathrm{C}$.

Table 1. Composition and characteristics of the protein fat simulator

\begin{tabular}{|l|c|}
\hline \multicolumn{1}{|c|}{ Indicator } & Value \\
\hline Taste and aroma & $\begin{array}{c}\text { Pure, milky, with light nutty } \\
\text { aroma }\end{array}$ \\
\hline Appearance, consistency & $\begin{array}{c}\text { Thick, opaque, homogenous } \\
\text { liquid }\end{array}$ \\
\hline Color & White \\
\hline Mass fraction of dry solids, \% & $14.4-14.5$ \\
\hline Mass fraction of protein, \% & $7.6-7.7$ \\
\hline Mass fraction of fat, \% & $0.06-0.07$ \\
\hline Mass fraction of lactose, \% & $4.5-4.6$ \\
\hline Lactic acid, \% & $0.35-0.39$ \\
\hline $\begin{array}{l}\text { Mass fraction of calcium, mg } \\
\%\end{array}$ & $127-133$ \\
\hline Titratable acidity, ${ }^{\circ} \mathrm{T}$ & $21-22$ \\
\hline Viscosity, $\mathrm{mPa} \cdot \mathrm{c}$ & $12.5-13.2$ \\
\hline
\end{tabular}

Table 2. Composition of the samples of normalized mixture

\begin{tabular}{|c|c|c|c|c|c|}
\hline Indicator & \multicolumn{5}{|c|}{ Value } \\
\cline { 2 - 6 } & control & \multicolumn{3}{|c|}{ microparticulate share, \% } \\
\cline { 4 - 6 } & 8.4 & 8.7 & 9.0 & 9.3 & 9.6 \\
\hline $\begin{array}{c}\text { Non-fat milk solids } \\
\text { (MSNF) \% }\end{array}$ & & & & & \\
\hline $\begin{array}{c}\text { Mass fraction of protein, } \\
\%\end{array}$ & 2.9 & 3.1 & 3.2 & 3.6 & 3.8 \\
\hline $\begin{array}{c}\text { Mass fraction of calcium, } \\
\text { mg \% }\end{array}$ & 122.0 & 121.5 & 121.9 & 121.3 & 121.8 \\
\hline Casein / rennet protein & $80 / 20$ & $76 / 24$ & $73 / 27$ & $70 / 30$ & $67 / 33$ \\
\hline
\end{tabular}

The use of the microparticulate led to an increase in the proportion of whey proteins, while the content of casein did not change. This led to the "dilution" effect, when the proportion of $\chi$-casein interacting with chymosin in the total dry matter mass decreases, thereby having a negative effect on the rennet coagulation rate. So, when $10 \%$ of the microparticulate was added to the normalized milk mixture, the duration of rennet coagulation increased by an average of $30 \%$, with the addition of $20 \%$ of the microparticulate - by more than $100 \%$.

The change in the dynamic viscosity of the samples of the normalized mixture was determined from the moment the coagulant was added and until the onset of syneresis (Fig. 1).

At the first stage of rennet coagulation, enzymatic cleavage of $\chi$-casein molecules occurs. The introduction of a protein fat simulator does not change the duration of the induction period of coagulation and does not interfere with the interaction of the enzyme and substrate, since the particles of the microparticulate whey proteins do not interact with chymosin. The onset of gelation is evidenced by an increase in the viscosity of the normalized milk mixture approximately 20 minutes after the addition of the milk-clotting enzyme. Paracasein particles form chains, which allows for visual marking of the beginning of the formation of rennet clot. 
Particles of microparticulate, like fat globules, penetrate into the voids of the structure of rennet coagulus. Remaining in the cells, the trapped particles of the microparticulate have a negative effect on the rheological properties of the gel through softening it. The strength value of the formed clot decreased with the addition of $10 \%$ of the microparticulate by $20 \%$, while using $15 \%$ of the microparticulate caused the decrease of strength by $30 \%$. Thus, with a mass fraction of microparticles of more than $10 \%$, a flabby clot formed, which is extremely difficult to undergo further processing to obtain elastic cheese grain. By directed influence on the technological parameters of coagulation, clot hardening can be achieved by creating favorable conditions for producing cheese characterized by standard quality.

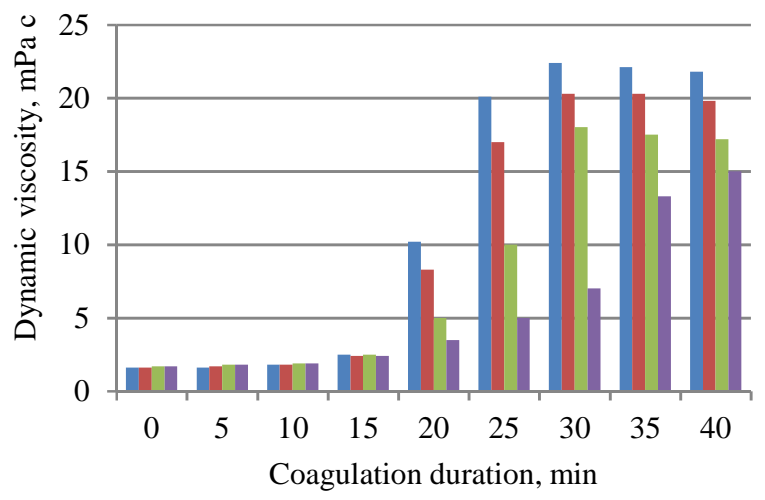

a Control $\quad \square \% \quad \square 10 \% \quad \square 15 \%$

Fig. 1. The effect of mass fraction of the fat simulant on the change in dynamic viscosity pf normalized milk mixture during rennet coagulation

The finished clot was cut into $8-10 \mathrm{~mm}$ cubes. The setting of the grain lasted for 15 to 20 minutes, then the grain was kneaded. The temperature of the second heating was $41-42{ }^{\circ} \mathrm{C}$, the duration was $30-40$ minutes. The resulting cheese grain during the entire technological process was characterized by a higher moisture content in comparison with the grain of the control sample (Fig. 2).

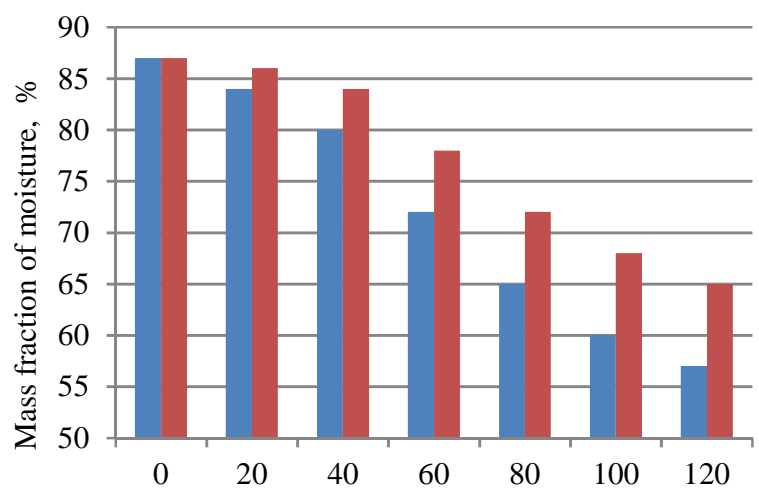

Total duration of grain processing, $\min$

- Control $\quad$ Cheese with microparticulate

Fig. 2. Dynamics of cheese grain dehydration
The high water-binding ability of whey proteins in the composition of microparticulates hindered dehydration.

Salting of Rossiysky cheese, according to the standard technology, was carried out in grain, molding in bulk, which contributed to the formation of a specific mesh pattern of cheese. Cheese got additional salt in brine for 2 to 3 days. The ripening duration of Rossiysky cheese was 60 days.

High hydration of whey proteins increased the moisture content in the cheese mass after pressing and in the ripening process (Fig. 3). Thus created favorable conditions for the life of microflora of starter cultures intensified biochemical processes during maturation, which is of great importance in the formation of specific organoleptic characteristics of cheese.

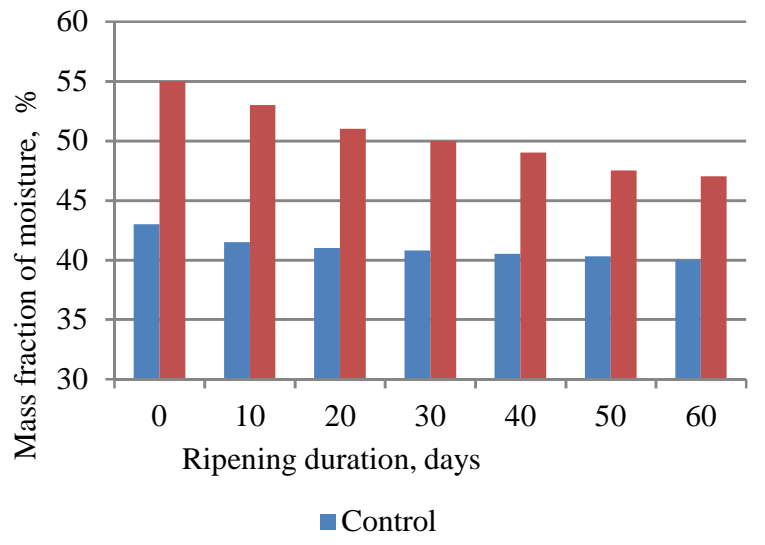

Fig. 3. Change of mass fraction of moisture in the cheese samples during ripening

Under the influence of lactic acid bacteria, glucose formed during the hydrolysis of lactose is converted into lactic acid. In Rossiysky cheese, glucose is completely fermented already for 2-3 days of rupening. At the same time, the number of lactococci reaches its maximum value. Further, their number decreases sharply. Their death is accompanied by autolysis of cells and the release of intracellular enzymes, characterized by high proteolytic activity. The enzymes of the microflora of lactococcal starter cultures are the main factor in the ripening of cheeses with a low temperature of second heating, including Rossiysky. Their total number is proportional to the amount of microflora in the cheese.

During ripening, hydrolysis of paracasein occurs. If paracasein breaks down into peptones and polypeptides under the action of a milk-clotting enzyme introduced before coagulation, then endoenzymes of lactic acid microorganisms cause a deeper breakdown with the formation of amino acids. The amount of soluble nitrogenous compounds is continuously increasing. A decrease in the number of mesophilic lactic acid lactococci is accompanied by an increase in the content of lactic acid bacilli. Their reproduction is due to the ability to assimilate lactates as a carbon source.

Based on the level of soluble nitrogen (Fig. 4), it was found that the hydrolysis of paracasein and its fractions proceeds more intensively in cheese with microparticulate. This is due to the high moisture content in the cheese with microparticulate in comparison with a 
traditionally produced cheese. Moisture is a factor in increasing the number of lactic acid microorganisms that initiate biochemical changes in cheese during ripening. Besides, it helps to reduce the resistance to diffusion processes, thereby increasing the efficiency of the transport of enzymes to the substrate.

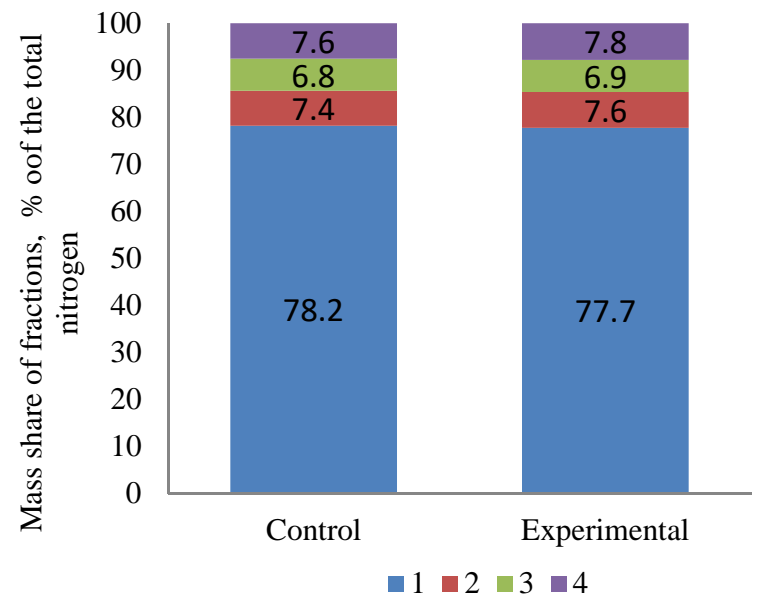

Fig. 4. Concentration of nitrogenous compounds in the control and experimental samples of cheese: 1 - unsoluble nitrogen, 2 - protein nitrogen, 3 - peptide nitrogen, 4 - amine and ammonia nitrogen

In accordance with the regulatory documents of the Russian Federation, Rossiysky cheese refers to cheeses with a low temperature of the second heating and is characterized by the following key indicators: it has a firm crust without damage, moderately elastic, uniform consistency, pronounced cheesy, slightly sour taste and aroma. The section shows the color of cheese from white to light yellow; the pattern consists of irregular and angular caverns, evenly distributed throughout the cheese mass. The mass fraction of fat in the dry matter of cheese, in accordance with regulatory documentation, is $(50 \pm 1.6) \%$, moisture not higher than $46 \%$, table salt from 1.3 to $1.8 \%$ inclusive. Active acidity of Rossiysky cheese is $5.15-5.35 \mathrm{pH}$.

The developed product is characterized by a higher value of the moisture content (Table 3), which, together with the retention of the clot of microparticulate particles by the mesh structure, increases the yield of cheese. The use of microparticulates led to an improvement in the consistency of cheese. The prototype was characterized as creamier and softed in comparison with the control.

Table 3. Quality indicators of the developed cheese

\begin{tabular}{|c|c|}
\hline Indicator & $\begin{array}{c}\text { Indicator value } \\
\text { for the cheese }\end{array}$ \\
\hline Mass fraction of fat in the solid matter, \% & 50.0 \\
\hline Mass fraction of moisture, \% & 47.1 \\
\hline Mass fraction of sodium chloride, \% & 1.5 \\
\hline Active acidity, pH & 5.19 \\
\hline Cheese yield, $\mathrm{kg} / 100 \mathrm{~kg}$ of milk & 14.4 \\
\hline
\end{tabular}

To assess the storage stbility of the obtained product in the sample laid for storage, we evaluated the change in titratable and active acidity, organoleptic properties, and controlled microbiological parameters. It was found that the use of microparticulate in the composition of rennet semi-hard Rossiysky cheese reduces its storage capacity by an average of $17 \%$. This is explained by a higher moisture content in the finished product compared to the one traditionally produced.

\section{Discussion}

The performed studies confirmed the possibility of replacing part of the normalized mixture for the production of semi-solid rennet Rossiysky cheese with a microparticulate whey protein. The presence of the protein fat simulat had a negative effect on the rennet coagulation process, since it reduced the proportion of casein contained in the total of solids, increasing the proportion of whey proteins. The decrease in rennet coagulation rate, as well as clot strength, confirms the advisability of using no more than $10 \%$ of microparticulate in a normalized milk mixture. To obtain the standard duration of rennet coagulation, as well as condensation of the clot, a modification of technological parameters is proposed: temperature $35{ }^{\circ} \mathrm{C}, \mathrm{pH} 6.4$, the proportion of milk-clotting enzyme preparation $0.04 \%$, and the addition of calcium chloride at the rate of $40 \mathrm{~g}$ of anhydrous salt per $100 \mathrm{~kg}$ of normalized milk mixture. As a result of further processing, fresh cheese is formed, the mass fraction of moisture in which exceeds the corresponding value for the control sample. An increased proportion of moisture is retained in the cheese during ripening and in the mature product. This affects the duration of maturation, creating the possibility of its reduction. An increase in the mass fraction of moisture, as well as an increase in the proportion of whey proteins introduced into the cheese with the microparticulate, increase the yield of the product. A high moisture content in the cheese leads to a slight reduction in its storage stability.

\section{Conclusion}

The developed technology of rennet semi-hard Rossiysky cheese with the microparticulate whey protein allows one to replace some of the expensive raw materials with a whey modification product. This helps to reduce the cost of cheese, and allows returning some of the byproduct of the industry into the main production.

\section{References}

1. E. Mihaleva, Whey. Development potential of the Russian Market, Milk river, 4, 14-18 (2018)

2. Talha Ahmad, Rana Muhammad Aadil, Haassan Ahmed, Ubaid ur Rahman, Bruna C.V. Soares, Treatment and utilization of dairy industrial waste: A review, Trends in Food Sci. \& Technol., 88, 361-372 (2019). DOI: 10.1016/j.tifs.2019.04.003

3. G.B. Gavrilov, Methods of rational use of milk whey, Milk Industry, 7, 32-33 (2012)

4. A.G. Khramtsov, Milk whey phenomenon (Professia Publ., St. Petersburg, 2011), 900 p. 
5. Ruann Janser Soaresde Castro, Maria Aliciane Fontenele Domingues, André Ohara, Paula Kiyomi Okuro, Jessika Gonçalvesdos Santos, Ramon Peres Brexó, Whey protein as a key component in food systems: Physicochemical properties, production technologies and applications, Food Struct., 14, 17-29 (2017). DOI: 10.1016/j.foostr.2017.05.004

6. I.A. Smirnova, I.V. Romanovskaya, V.K. Shtrigul, Method of obtaining microparticulated casein and the possibility of its application in the production of nonfat fermented milk products, Foods and Raw Mater., 26.1 (2013)

7. M.L. Olivares, K. Shahrivar, J. de Vicente, Soft lubrication characteristics of microparticulated whey proteins used as fat replacers in dairy systems,
J. of Food Engineer., 245, 157-165 (2019). DOI: 10.1016/j.jfoodeng.2018.10.015

8. R. Ipsen, Microparticulated whey proteins for improving dairy product texture, Int. Dairy J., 67, 73-79 (2017). DOI:10.1016/j.idairyj.2016.08.009

9. E.I. Melnikova, E.B. Stanislavskaia, A.N. Losev, Microparticulation of Caseic Whey to Use in Fermented Milk Production, Foods and Raw Mater., 5(2), 83-93 (2017)

10. O.V. Dymar, Technological aspects of whey protein microparticulate use in food production, J. Dairy Ind., 6, 19-21 (2014)

11. E.I. Melnikova, E.B. Stanislavskaia E.G. Korotkov, Preparation and use of whey proteinmicroparticulate in synbiotic drink technology, Foods and Raw Mater., 3 (2015) 